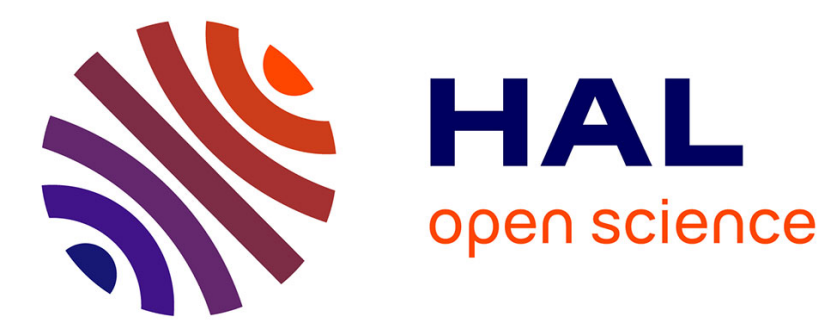

\title{
Experimental study of mass transfer in a dense bubble swarm
}

\author{
Damien Colombet, Dominique Legendre, Arnaud Cockx, Pascal Guiraud, \\ Frederic Risso, Claude Daniel, Sophie Galinat
}

\section{- To cite this version:}

Damien Colombet, Dominique Legendre, Arnaud Cockx, Pascal Guiraud, Frederic Risso, et al.. Experimental study of mass transfer in a dense bubble swarm. Chemical Engineering Science, 2011, 66 (14), pp.3432-3440. 10.1016/j.ces.2011.01.020 . hal-02115985

\section{HAL Id: hal-02115985 \\ https://hal.science/hal-02115985}

Submitted on 14 Jan 2021

HAL is a multi-disciplinary open access archive for the deposit and dissemination of scientific research documents, whether they are published or not. The documents may come from teaching and research institutions in France or abroad, or from public or private research centers.
L'archive ouverte pluridisciplinaire HAL, est destinée au dépôt et à la diffusion de documents scientifiques de niveau recherche, publiés ou non, émanant des établissements d'enseignement et de recherche français ou étrangers, des laboratoires publics ou privés. 


\title{
Experimental study of mass transfer in a dense bubble swarm
}

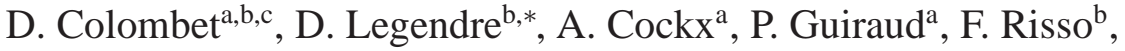 \\ C. Daniel ${ }^{\mathrm{c}}, \mathrm{S}$. Galinat ${ }^{\mathrm{c}}$, \\ ${ }^{a}$ Université de Toulouse; INSA, UPS, INP; LISBP, 135 Avenue de Rangueil \\ F-31077 Toulouse, France \\ INRA, UMRA792 Ingénierie des Systèmes Biologiques et des Procédés \\ F-31400 Toulouse, France \\ CNRS, UMR5504, F-31400 Toulouse, France \\ ${ }^{b}$ Université de Toulouse; INPT, UPS; IMFT (Institut de Mécanique des Fluides de Toulouse) \\ Allée Camille Soula, F-31400 Toulouse, France \\ CNRS ; IMFT ; F-31400 Toulouse, France \\ ${ }^{c}$ Rhodia Operations, 85, Avenue des Frères Perret, BP 62, 69192 Saint Fons, France
}

\begin{abstract}
We consider the liquid-side mass transfer coefficient $k_{L}$ in a dense bubble swarm for a wide range of gas volume fraction $\left(0.45 \% \leq \alpha_{G} \leq 16.5 \%\right)$. The study is performed for an air-water system in a square column. Bubble size, shape and velocity have been measured for different gas flow rates by means of a high speed camera. Gas volume fraction and bubble velocity have also been measured by a dual-tip optical probe. Both of these measurements show that the bubble vertical velocity decreases when increasing $\alpha_{G}$ in agreement with previous investigations. The mass transfer is measured from the time evolution of the dissolved oxygen concentration, which is obtained by the gassing-out method. The mass transfer coefficient is found to be very close to that of a single bubble provided the bubble Reynolds number is based on the average equivalent diameter $\left\langle d_{e q}\right\rangle$ and the vertical slip velocity $\left\langle V_{z}\right\rangle$.
\end{abstract}

Keywords: Bubble columns - Mass Transfer - Hydrodynamics

\section{Introduction}

Bubbly flows are widely present in industrial mass transfer processes because of their high interfacial area. In most gas-liquid reactors, the gas volume fraction can have average values larger than 10 or $20 \%$ and locally reach much larger values. For such high void fractions, the fluid agitation is known to be significantly controlled by bubble induced turbulence (Lance \& Bataille, 1991; Riboux et al. , 2010) and bubbles can not be considered as isolated. One significant effect is the decrease of the bubble rise velocity when increasing the gas volume fraction. One question of importance for such systems concerns the induced effect on the mass transfer. Despite the high gas volume fractions observed in industrial applications, numerous investigations have used mass transfer models without considering effect of gas volume fraction. They are based on the Higbie's

\footnotetext{
*legendre@imft.fr
} 
penetration theory (Higbie (1935)) where the liquid-side mass transfer coefficient $k_{L}$ depends on the molecular diffusion coefficient $D_{L}$ and a characteristic time $t_{c}$ as

$$
k_{L}^{H i g}=\frac{2}{\sqrt{\pi}} \sqrt{\frac{D_{L}}{t_{c}}},
$$

where $t_{c}$ is the so-called exposure or contact time. It represents the characteristic time of transfer by the fluid motion and it is also presented as the residence time of fluid particles at the interface. Different models can be found for $t_{c}$. It has been expressed as the ratio of the bubble diameter to the bubble rise velocity, the bubble surface area to the rate of surface area formation or using eddy fluctuations velocity (Nedeltchev et al. (2007); Huang et al. (2010)).

In most of the studies dedicated to bubbly reactors, the contact time is defined as $t_{c}=d_{e q} / V_{z}$ where $d_{e q}$ is the bubble equivalent diameter and $V_{z}$ is the bubble rising velocity. With such a definition, the normalized transfer coefficient, when expressed using the Sherwood number $S h=$ $k_{L} d_{e q} / D_{L}$, is equivalent to the analytical solution obtained by considering the potential flow around a spherical clean bubble having the same diameter and terminal velocity (Boussinesq, 1905):

$$
S h^{B}=\frac{2}{\sqrt{\pi}}(R e S c)^{1 / 2}=\frac{2}{\sqrt{\pi}} P e^{1 / 2}
$$

where $R e=d_{e q} V_{z} / \nu_{L}$ is the bubble Reynolds number and $S c$ is the Schmidt number. This solution assumes a thin concentration boundary layer thickness, which is valid at large Peclet numbers $P e=$ $R e S c$. The Boussinesq solution is known to be very accurate to describe mass transfer for the case of isolated (or very dilute) clean spherical bubbles rising in a liquid at a large bubble Reynolds number (Figueroa \& Legendre, 2010). Boussinesq solution (2) has been used as closure law in Eulerian-Eulerian two fluid models to simulate industrial ozonation towers (Cockx et al. , 1999) and aeration tanks for urban wastewater treatment (Fayolle et al. , 2007) for low and moderate gas volume fractions $\left(\alpha_{G} \leq 10 \%\right)$.

As indicated above, expression (2) is theoretically limited to large bubble Reynolds numbers and isolated spherical bubbles. Some corrections based on single bubble results have been introduced for simulating bubble columns in order to account for finite Reynolds number effect (Darmana et al. , 2005; Shimada et al. , 2007; Ayed et al. , 2007) and bubble deformation (Nedeltchev et al. , 2007). Such corrections for single bubble mass transfer are discussed in Takemura \& Yabe (1998) and Figueroa \& Legendre (2010). General reviews for mass transfer with bubbles can be found in Clift et al. (1978); Michaelides (2006). Most of these studies focused on single bubbles. Their relevance to dense bubbly flow has not yet been proved. Concurrently, bubble induced agitation has been investigated (Garnier et al. , 2002; Zenit et al. , 2001; Riboux et al. , 2010) but its impact on the transfer was not considered. This is the objective of the experimental study reported in this paper. For this purpose, accurate measurement of oxygen mass transfer, interfacial area, bubble diameter and bubble slip velocity are performed over a wide range of gas volume fraction $\left(0.45 \leq \alpha_{G} \leq 16.5 \%\right)$.

\section{Experimental methods}

\subsection{Experimental set-up and instrumentation}

We consider the transfer of oxygen from dispersed air bubbles into water. Experiments are performed at ambient temperature and pressure. Tap water filtered to remove particles larger than 
$15 \mu \mathrm{m}$ is used in all the presented experiments. However, the gas-liquid system can be considered to be close to a clean system since terminal velocity of single bubbles was checked to be the same as that obtained in ultra pure water. The main physical properties of the system are summarized in table 1.

The experimental set-up is described in detail in Riboux et al. (2010). It consists in injecting bubbles in a square $(15 \times 15 \mathrm{~cm})$ glass column of $100 \mathrm{~cm}$ high. The gas line is equipped with three different rotameters (Brooks) to give access to a large range of gas flow rates and gas volume fraction. A three way valve has been added to switch from nitrogen to air. An homogeneous bubble swarm is generated by means of 841 capillaries of $15 \mathrm{~cm}$ long and inner diameter $d_{c}=0.2 \mathrm{~mm}$.

\subsubsection{Shadow casting method}

A high speed CMOS camera (Photron APX) with a fixed-focus lens is employed (Fig. 1). The camera is operated at 500 images per second with an exposure time varying from $1 / 20000$ to $1 / 500 s$ depending on the lighting method.

For low gas volume fraction, lighting is supplied by a $100 \times 100 \mathrm{~mm}$ diode backlight of $65700 \mathrm{~cd} \mathrm{~m}^{2}$. For high gas volume fraction an halogen spot of $1000 \mathrm{~W}$ is required.

The shadow casting set-up consists in using a $105 \mathrm{~mm}$ fixed-focus lens Nikon to visualize a field located at $15 \mathrm{~mm}$ to the wall in the $x$-direction, in the center of the column in the $y$-direction and at a distance of $150 \mathrm{~mm}$ from the injectors tips in the vertical $z$-direction. For this set-up, dimensions of the view field are $18 \times 18 \mathrm{~mm}$ and the resolution is $56.8 \mathrm{px} / \mathrm{mm}$. The diaphragm aperture is adjusted to offer a thin depth of field $(0.8 \mathrm{~mm})$, which allows to detect only the bubbles that cross the field of view.

\subsubsection{Dual-tip optical probe}

To measure gas volume fraction $\alpha_{G}$ and the vertical bubble velocity $V_{z}$, a dual-tip optical fiber probe (RBI Instrumentation) is introduced in the center of the column. A threshold just higher than the signal noise is first applied on the raw signal. Then the gas volume fraction is calculated by

$$
\alpha_{G}=\frac{\sum \Delta t_{y i}}{t_{a q c}}
$$

where $t_{a q c}$ is the acquisition duration and $\Sigma \Delta t_{y i}$ the total time during which the probe has detected the gas phase, $\Delta t_{y i}$ corresponding to the detected duration of bubble $i$. The signal acquisition is performed with a sampling frequency of $10 \mathrm{kHz}$. Gas volume fraction measurements shows a good convergence for a recording time larger than $800 \mathrm{~s}$. An accuracy better than $2 \%$ is obtained.

Knowing the distance $d_{s}=1 \mathrm{~mm}$ between the two optical fibbers and the time interval $\Delta t_{12 i}$ between the successive detections of the same interface by the two fibers, the vertical velocity $V_{z i}$ of bubble $i$ is obtained by

$$
V_{z i}=\frac{d_{s}}{\Delta t_{12 i}}
$$

The main difficulty of the measurement is to match the two successive rising fronts that correspond to the piercing of the same bubble. Various parasite cases may generate very high or very low measured velocities. As a result, it is necessary to define realistic maximum and minimum velocities. According to previous tests (Riboux, 2007), a maximal velocity $V_{\max }=0.7 \mathrm{~m} \mathrm{~s}^{-1}$ and a minimal velocity $V_{\text {min }}=0.03 \mathrm{~m} \mathrm{~s}^{-1}$ have been chosen. 


\subsubsection{Particle tracking velocimetry (PTV)}

The tracking method is based on the comparison of bubble center positions between consecutive images. To improve the number of successive images where a given bubble is detected, a predicting trajectory algorithm is employed. The recorded images are proceeded using Matlab ${ }^{\circledR}$. A typical shadow casting raw image with bubble detection is presented in Fig. 2 for different gas volume fractions. As the gas flow rate increases, the number of bubble rising between the focus field and the column wall increases. The detection thus becomes difficult since those blurred bubbles mask the bubble located in the visualization field. As a consequence, the present results are limited to gas volume fraction less than $16.5 \%$. Beyond this value the detection of bubbles is not possible by this method.

The bubbles are assumed to be oblate spheroid with a minor semi-axis $a$, a major semi-axis $b$ and aspect ratio $\chi=b / a$. The volume of a detected bubble is $V_{b}=4 \pi b^{2} a / 3=\pi d_{e q}^{3} / 6$, so the equivalent diameter is

$$
d_{e q}=\left(8 b^{2} a\right)^{1 / 3}
$$

and the bubble area $S_{b}$ can be expressed as (Beyer, 1987)

$$
S_{b}=\pi \frac{d_{e q}^{2}}{4}\left(2 \chi^{2 / 3}+\frac{\chi^{-4 / 3}}{\sqrt{1-\chi^{-2}}} \ln \left(\frac{1+\sqrt{1-\chi^{-2}}}{1-\sqrt{1-\chi^{-2}}}\right)\right)
$$

\subsubsection{Interfacial area measurement}

For a given volume of the column $V_{t o t}$, the volumetric interfacial area is $a_{I}=\sum S_{b} / V_{\text {tot }}$ and is linked to the gas volume fraction $\alpha_{G}=\sum V_{b} / V_{\text {tot }}$ by the relation:

$$
a_{I}=\alpha_{G} \frac{\sum S_{b}}{\sum V_{b}}
$$

where $V_{b}$ is the bubble volume. As indicated above, for each bubble detected, $a$ and $b$ are obtained from the images used to determine the bubble volume $V_{b}$ and surface $S_{b}$. On the other hand, the gas volume fraction $\alpha_{G}$ is given by the optical probe. Then, the interfacial area $a_{I}$ is determined by using Eq. (7).

\subsection{Mass transfer measurement}

During the oxygenation step, the concentration of dissolved oxygen in water is measured by using a fast time response probe (Clark type micro-sensor, Unisense Ox50). The concentration measurement is based on the measurement of the electrical intensity between an anode and an oxygen reducing cathode. This intensity (in pico Ampere) is proportional to the oxygen concentration in the media. The oxygen probe is placed at the halfway of the swarm.

Oxygen saturation concentration. At the bubble interface, the concentrations of the species on each side (liquid and gas) are controlled by the Raoult's law and the Henry's law. When a gas bubble is injected in a liquid, the liquid-vapor equilibrium controls the vapor concentration of water in the bubble. This equilibrium is governed by the Raoult's law that relates the molar fractions $\left(x_{\mathrm{H}_{2} \mathrm{O}}^{G}, x_{\mathrm{H}_{2} \mathrm{O}}^{L}\right.$ ) of water through the gas and liquid fugacity equalities. Considering that the liquid is essentially composed of water $x_{H_{2} \mathrm{O}}^{L} \approx 1$ and that activity and fugacity coefficients are equals to unity, the Raoult's law simplifies to

$$
x_{H_{2} O}^{G}=P^{s a t} / P
$$


where $P^{s a t}$ stands for the saturation pressure of water that depends essentially on the temperature. $P$ is the gas phase pressure that is taken equal to the liquid phase pressure by neglecting the Laplace pressure jump. Considering the molar fraction of oxygen in dry air $x_{\mathrm{O}_{2}}^{G 0}$ and assuming that the liquid-vapor equilibrium is reached instantaneously, the molar fraction of oxygen in bubble is then

$$
x_{O_{2}}^{G}=x_{O_{2}}^{G 0}\left(1-x_{H_{2} O}^{G}\right)=x_{O_{2}}^{G 0}\left(1-P^{s a t} / P\right)
$$

The species concentration jump at the interface is given by the Henry's law. Considering an ambiant pressure and a low solubility of oxygen in water, Henry's law gives the relation between the oxygen concentration in the gas $x_{\mathrm{O}_{2}}^{G}$ and in the liquid $x_{\mathrm{O}_{2}}^{L}$ at the bubble interface

$$
x_{O_{2}}^{L}=x_{O_{2}}^{G} P / H e
$$

where $\mathrm{He}$ (here in $\mathrm{Pa}$ ) is the Henry constant of oxygen in water and is essentially depending on temperature. Using Eq. 9, the above molar fraction jump can finally be expressed as

$$
x_{O_{2}}^{L}=x_{O_{2}}^{G 0} \frac{\left(P-P^{s a t}\right)}{H e}
$$

Considering the data reported in Table 1, the molar fraction of oxygen in the liquid phase is very small $x_{\mathrm{O}_{2}}^{L}=5.1210^{-6}$. Consequently, the oxygen saturation mass concentration is related to the oxygen saturation molar concentration as

$$
C_{L s}(z)=x_{O_{2}}^{G 0} \rho_{H_{2} O} \frac{M_{O_{2}}}{M_{H_{2} O}} \frac{\left(P-P^{s a t}\right)}{H e}
$$

Pressure influence. It can be noticed that the oxygen concentration depends on the local total pressure $P$. In a tall bubble column, the vertical pressure gradient due to hydrostatic pressure can influence the local saturation concentration (Camacho Rubio et al. , 1999). In the column, the mean pressure evolves vertically as $P(z)=P^{a t m}+\left(1-\alpha_{G}\right) \rho_{L} \overline{g(H-z)}$ where $z=0$ corresponds to the injectors tip, $H$ is the height of the swarm and $P^{a t m}$ is the atmospheric pressure at the upper liquid surface. The pressure and the oxygen saturation concentration are maximal at the injector level due to water weight. For a very low gas volume fraction $\left(\alpha_{G} \approx 0\right)$ and a height of liquid $H=70 \mathrm{~cm}$, the maximal variation of the oxygen saturation concentration is only $6.4 \%$ (Eq. 12).

Oxygen concentration depletion influence. In recent investigations on airlift reactors, the oxygen depletion in bubble was found to strongly influence global mass transfer (Talvy et al. , 2007). The oxygen concentration in a bubble along its path from the injectors to the upper liquid surface varies due to the mass transfer that generates a depletion of the bubble oxygen concentration. In a Lagrangian point of view, the variation of the oxygen concentration $C_{G}$ in a single gas bubble can be expressed as

$$
\frac{d C_{G}}{d t}=-\frac{S_{b}}{V_{b}} k_{L}\left(C_{L s}-C_{L B u l k}\right)
$$

where $C_{L B u l c k}$ is the liquid bulk concentration. The maximum variation of the oxygen concentration in a bubble is observed at the beginning of the experiment since there is no oxygen in the bulk $\left(C_{L B u l k}=0\right)$. To estimate this variation, we consider a bubble generated from a single capillary in 
quasi-static bubbling regime where $d_{e q 0}=2.1 \mathrm{~mm}, \chi_{0}=1.7, V_{z 0}=0.32 \mathrm{~m} . \mathrm{s}^{-1}$ (Riboux et al. , 2010). The bubble resident time in the column is estimated as $t_{s} \approx H / V_{z 0}=2.18 \mathrm{~s}$. The oxygen concentration variation in the bubble is estimated using the relation (2) to calculate the transfer coefficient. The variation is found to be around $6 \%$ compared to the value at the middle-height of the column. During the oxygenation experiments, the variation of the oxygen in the bubble decreases since the liquid bulk concentration $C_{L B u l k}$ increases with time.

Nitrogen mass transfer influence. In this study we have a ternary system and nitrogen may undergo also mass transfer to or from the bubble. Before any experiment, the bubbling of pure nitrogen in the water is used to remove oxygen and it imposes an initial saturation concentration of nitrogen $C_{L}^{N_{2}}(t=0)=18.84 \mathrm{mgL}^{-1}$ in the liquid. When switching from Nitrogen to air, the gas composition changes from $x_{N_{2}}^{G 0}=1$ to $x_{N_{2}}^{G 0}=0.791$ and nitrogen transfers from the liquid to the gas until the concentration of nitrogen in the liquid reaches the value corresponding to the new molar gas fraction of nitrogen $C_{L}^{N_{2}}(t=\infty)=14.89 \mathrm{mgL}^{-1}$. In the bubbles, the effect of this nitrogen mass transfer is the dilution of the oxygen concentration due to the increase of nitrogen concentration. A simple estimate of the impact of the nitrogen liquid to gas mass transfer on the oxygen gas concentration is done by considering that the oxygen is not transferring. Then, the variation of the nitrogen concentration of one bubble has been calculated using equation 13 with $C_{L s}=C_{L}^{N_{2}}(t=\infty)$ and $C_{L B u l k}=C_{L}^{N_{2}}(t=0)$. Due to the value of the nitrogen diffusion coefficient in water $D_{L}^{N_{2}}$ given in table 1, the mass transfer coefficient is calculated using relation (2). Assuming a constant bubble volume, the nitrogen concentration variation in the bubble is found to be less than $1.6 \%$ from $C_{G}^{N_{2}}=899.8 \mathrm{mg} \mathrm{L}^{-1}$ at the bottom to $C_{G}^{N_{2}}=914.5 \mathrm{mg} \mathrm{L}^{-1}$ at the top of the column. As a result, $C_{G}(t=0)=272.38 \mathrm{mg} \mathrm{L}^{-1}$ to $C_{G}\left(t=t_{s}\right)=268.99 \mathrm{mg} \mathrm{L}^{-1}$ so that the dilution of the oxygen gas concentration due to nitrogen mass transfer is less than $1.3 \%$. Consequently, we neglect in this work the effect of nitrogen mass transfer.

Finally, due to the weak influence of the pressure and of the gas concentration depletion, the oxygen saturation concentration can be reasonably considered as constant after several seconds and equals to the concentration at the upper surface $\left(P=P^{a t m}\right)$ :

$$
C_{L s}^{*}=C_{L s}(z=H)=9.08 m g L^{-1}
$$

Transfer time scale. The classical gassing-out method is used to deduce the transfer time scale. This method consists in first bubbling nitrogen gas in the column in order to remove the oxygen naturally present in water. Secondly, without changing the gas flow-rate and the bubble injection dynamics, air is suddenly injected in the column and the dissolved oxygen concentration increases until the saturation of oxygen in the liquid is achieved. The analysis of the time evolution of the oxygen concentration is then used to obtain the mass transfer time scale.

The small liquid volume and the efficient liquid mixing caused by bubble induced turbulence both contribute to an efficient liquid mixing. The bubble column is thus assumed to be a perfectly mixed reactor. In such a condition, the variation of the liquid oxygen concentration $C_{L}$ is described by

$$
\frac{\partial C_{L}}{\partial t}=\frac{k_{L} a_{I}}{\left(1-\alpha_{G}\right)}\left(C_{L s}^{*}-C_{L}\right)
$$


where $k_{L}$ is the liquid-side mass transfer coefficient and $a_{I}$ is the interfacial area. The oxygen probe response time $\tau_{p}$ needs also to be taken into account (Letzel et al. , 1999; Martin et al. , 2007). For this purpose, the behavior of the oxygen probe is assumed to evolve as a first order system

$$
\frac{\partial C_{p}}{\partial t}=\left(1 / \tau_{p}\right)\left(C_{L}-C_{p}\right)
$$

The resolution of the probe signal (Eq. 16) and the oxygen concentration (Eq. 15) leads to

$$
\frac{C_{p}}{C_{L s}^{*}}=1-\frac{1}{\left(\tau-\tau_{p}\right)}\left(\tau e^{-t / \tau}-\tau_{p} e^{-t / \tau_{p}}\right)
$$

where $\tau$ is the transfer time scale corresponding to the relaxation time of mass transfer and is given by

$$
\tau=\frac{\left(1-\alpha_{G}\right)}{k_{L} a_{I}}
$$

For our experiments, a fast response time probe was used $\left(\tau_{p}=0.8 s\right)$ and the concentration measurements were performed with a sampling frequency of $20 \mathrm{~Hz}$.

\section{Results and discussions}

The PTV method provides the evolution of the bubble average equivalent diameter, the interfacial area and bubble velocity components on $x$ - and $z$ - axis. The dual-tip optical probe gives the gas volume fraction and bubble vertical ( $z$ - axis) velocity. Bubble surface area and hydrodynamic results are then combined with mass transfer measurements to access to the experimental transfer coefficient $k_{L}$. The values are finally compared to the transfer observed for a single bubble of same equivalent diameter and terminal rise velocity.

\subsection{Equivalent diameter and interfacial area}

The equivalent diameter can be extracted from bubble volumes (Eq. 5). The average equivalent diameter presented in Fig. 3a is found to increase with the gas volume fraction (or gas flow rate). This increase is mainly explained by the bubble formation conditions. At very low gas volume fraction, the formation can be consider as quasi-static and the bubble size can be predict by the equilibrium between buoyancy and capillary forces at the tip of the capillaries. Considering a contact angle of $90^{\circ}$, the static diameter can then be expressed using the Tate law

$$
d_{T}=\left[\frac{6 \sigma d_{c}}{\Delta \rho g}\right]^{1 / 3}
$$

As expected, at low gas hod-up, the equivalent diameter measured by the PTV method corresponds to the prediction of Eq. $19\left(d_{T} \approx 2.07 \mathrm{~mm}\right)$ and to previous experimental results of Riboux et al. (2010) $\left(d_{e q 0}=2.1 \mathrm{~mm}\right)$. For moderate gas flow rate, inertial effects (added mass) are involved in the forces balance experienced by the bubble. The resulting effect is an increase of bubble volume at detachment (Duhar \& Colin, 2006). For very high flow rate, bubble coalescence can take place just above the capillary tip (Manasseh et al. , 2008). The Log-Log representation used 
in Fig. 3a clearly reveals two different power-law evolutions. The diameter evolution observed in our experiments can be simply described by the following relations

$$
\begin{aligned}
& \frac{\left\langle d_{e q}\right\rangle-d_{e q 0}}{d_{e q 0}} \approx 15 \alpha_{G} \text { for } \quad \alpha_{G} \leq 2.4 \% \\
& \frac{\left\langle d_{e q}\right\rangle-d_{e q 0}}{d_{e q 0}} \approx 2.3 \alpha_{G}^{0.5} \text { for } \quad \alpha_{G} \geq 2.4 \%
\end{aligned}
$$

For a very similar bubble column and injection system but with different capillaries inner diameter $\left(d_{c}=0.15 \mathrm{~mm}\right)$, Martínez-Mercado et al. (2007) also observed an increase of bubble diameter with $\alpha_{G}$. The corresponding experiments are reported in Fig. 3a. It is interesting to note that both Eq. 20 and Eq. 21 with $d_{e q 0}=1.4 \mathrm{~mm}$ can also reproduce the diameter evolution reported by Martínez-Mercado et al. (2007).

From the experiments, the bubble aspect ratio has also been determined. It appears that the bubble aspect ratio is not significantly impacted by the gas volume fraction. It has been found to be nearly constant for the gas volume fractions considered in this study:

$$
\chi \approx 1.5
$$

The interfacial area $a_{I}$ is reported in Fig. $3 \mathrm{~b}$ and is found to increase significantly with the gas volume fraction. The corresponding evolution can be simply described by the following relation

$$
\frac{a_{I}}{a_{I 0}} \approx 0.341 \alpha_{G}^{0.805}
$$

where $a_{I 0}=S_{b} / V_{b}=310^{3} \mathrm{~m}^{-1}$ is the surface to volume ratio for a bubble of equivalent diameter $d_{e q 0}$ and aspect ratio $\chi_{0}$. However, it is important to stress here that these two relations (Eq. 20-22) are strongly dependent on the bubble generation set-up.

\subsection{Bubbles velocities}

During the last decade, bubble velocity in dense swarms has been investigated (Rusche \& Issa, 2000; Garnier et al. , 2002; Zenit et al., 2001; Riboux et al. , 2010). All these studies report a significant decrease of the average vertical velocity with the increase of the gas volume fraction. Experimentally, one of the major difficulties is to keep an homogeneous regime in order to avoid large-scale liquid circulations. In our column, it is observed that at gas volume fraction around 10 $\%$, large vertical liquid loops can be produced resulting in a churn turbulent bubbly flow and an unstable upper liquid surface. To avoid this phenomenon and stay in the homogeneous regime, the liquid volume in the column is reduced to maintain stable conditions. The corresponding values of the liquid height are reported in Table 2.

As shown in Fig. 4, the vertical velocities obtained with the dual-tip optical probe are in very good agreement with the previous results and correlations. In previous experiments, the vertical velocity was investigated using optical or resistive probes. In this work, the bubble velocity is also measured using non intrusive measurement (high speed camera). Results obtained with both methods are compared in Fig. 4. We observe a very satisfactory agreement between velocities measured with our PTV method and the classical optical probe method. The small underestimation observed for PTV results can be explained by wall effects and a correction could be deduced from 
measurement of wall velocity profiles in the column. Our results are found to be well described by the correlation proposed by Riboux et al. (2010)

$$
\left\langle V_{z}\right\rangle=V_{z 0}\left(1-\alpha_{G}^{0.49}\right)
$$

where $V_{z 0}$ is the rise velocity of an isolated bubble. Note that the correlations of Garnier et al. (2002) $\left\langle V_{z}\right\rangle=V_{z 0}\left(1-\alpha_{G}^{1 / 3}\right)$ predicts a velocity from 10 to $25 \%$ lower. This discrepancy could be explained by the fact that in our work (and other previous experimental studies in agreement with our results) no liquid flow rate is imposed.

PTV measurement also provides the average horizontal velocity $\left\langle V_{x}\right\rangle$. This component is reported in Fig. 4. We can observe that the averaged horizontal velocity is zero, showing that there is no horizontal mean bubble motion.

\subsection{Mass transfer}

Two typical time evolutions of oxygen concentration are presented in Fig. 5 for $\alpha_{G}=0.6$ and $15.2 \%$. The least square method is used to fit the experimental curves with Eq. 17 in order to obtain the transfer time scale $\tau$. The corresponding fitting curves are also reported in Fig. 5 and we can observe that the agreement is very good. The evolution of the oxygen concentration in our system is thus the one expected and described using equation Eq. 17, which can be used to determine the transfer time $\tau$.

The corresponding values of $\tau$ are reported in Fig. 6. It is shown that the time necessary to reach the liquid saturation decreases with the increase of the gas volume fraction since the interfacial area increases with the increase of $\alpha_{G}$. The decrease of $\tau$ is significant since one order of magnitude is found between the time to saturate for $\alpha_{G}<1 \%$ and $\alpha_{G}=16.5 \%$. The $\log -\log$ representation of Fig. 6 indicates that the transfer time decrease follows a very simple power law

$$
\tau \propto \alpha_{G}^{-0.74}
$$

The experimental mass transfer coefficient $k_{L}^{e x p}$ is then deduced from the value of $\tau$ :

$$
k_{L}^{e x p}=\frac{\left(1-\alpha_{G}\right)}{\tau a_{I}}
$$

The evolution of the experimental mass transfer coefficient $k_{L}^{e x p}$ is reported in Figure 7 for the gas volume fractions considered in this study. Firstly, it can be noted that despite a significant range of variation of the gas volume fraction (more than one decade), the same order of magnitude is observed for $k_{L}^{\exp } \approx O\left(10^{-4}\right) \mathrm{ms}^{-1}$. Consequently, for a rough estimation the mass transfer coefficient can be considered as constant.

Secondly, a detailed inspection of the evolution of $k_{L}^{\text {exp }}$ reveals that the mass transfer coefficient slightly decreases with the gas volume fraction. However, since both bubble diameters and rising velocities vary with $\alpha_{G}$ (see Fig. 3a and Fig. 4, respectively) it is not really possible to explain the origin of the decrease of $k_{L}^{e x p}$ with the gas volume fraction. Knowing the evolution of both the diameter and the rising velocity as functions of $\alpha_{G}$, it is possible to calculate for each gas volume fraction the transfer from an isolated bubble having the same diameter and the same rising velocity in order to discuss the effect of the gas volume fraction upon the transfer. This is the objective of the next section. 


\subsection{Comparison with single bubble mass transfer}

It is now possible to compare the evolution of the mass transfer coefficient $k_{L}^{\exp }$ with results obtained for isolated bubbles. For this purpose, we define the bubble Reynolds number as

$$
R e=\frac{\left\langle V_{z}\right\rangle\left\langle d_{e q}\right\rangle}{\nu_{L}}
$$

where $\left\langle V_{z}\right\rangle$ is obtained from correlation (23). A constant Schmidt number $S c=500$ is considered. The evolution of the diameter $\left\langle d_{e q}\right\rangle$ is calculated using Eq. 20-21. As indicated in the introduction, several expressions have been obtained in order to improve the Boussinesq analytical solution given by (2), which is limited to large bubble Reynolds numbers and spherical bubbles. Consequently, some corrections have been introduced to consider the effect of a finite Reynolds number and the effect of the bubble deformation. Among the expressions in the literature to consider the effect of the Reynolds number, we consider the solution obtained by Winnikow (1967), which is based on the velocity field derived by Moore (1963) (see Takemura \& Yabe (1998); Figueroa \& Legendre (2010)):

$$
S h^{W}=\frac{2}{\sqrt{\pi}}\left[1-\frac{2.89}{\sqrt{R e}}\right]^{1 / 2} P e^{1 / 2}
$$

For moderate Reynolds numbers and high Schmidt numbers, Takemura \& Yabe (1998) determined the mass transfer of bubbles of a few millimeters (almost spherical) by means of accurate timevarying diameter measurements. They proposed a semi-empirical relation in good agreement with both their experiments and their numerical simulations

$$
S h^{T Y}=\frac{2}{\sqrt{\pi}}\left[1-\frac{2}{3} \frac{1}{\left(1+0.09 R e^{2 / 3}\right)^{3 / 4}}\right]^{1 / 2}\left(2.5+P e^{1 / 2}\right)
$$

The second effect not considered in the Higbie model based on the contact time $t_{c}=d_{e q} / V_{z}$ is due to bubble deformation. Air bubbles in water are known to deform when their diameter is larger than $1 \mathrm{~mm}$. For a clean ellipsoidal bubble, Lochiel \& Calderbank (1964) have developed an analytical expression of the mass transfer coefficient using the potential solution around a spheroid of minor and major semi-axis noted $a$ and $b$, respectively:

$$
S h(\chi)=\frac{2}{\sqrt{\pi}} P e^{1 / 2} f(\chi)
$$

The function $f(\chi)$ accounts for the effect of the deformation. The validity of such solution has been recently discussed in Figueroa \& Legendre (2010). Based on direct numerical simulations this study reveals that, the Sherwood number is close (within about 10\%) to the Sherwood number of a spherical bubble with the same Peclet number. Figueroa \& Legendre (2010) proposed a simple correction function $f(\chi)$ to describe the effect of the deformation for $500<R e<1000$ and $S c>100$ :

$$
f(\chi)=0.524+0.88 \chi-0.49 \chi^{2}+0.086 \chi^{3}
$$

As indicated in section 3.1, the averaged deformation of a bubble is found to be almost constant for the gas volume fraction considered. A constant value $\chi \approx 1.5$ is used in the following to characterize bubble deformation. The corresponding correction is thus $f(\chi=1.5)=1.031$. 
The evolutions of the mass transfer coefficient $k_{L}$ obtained using relation (2) (Boussinesq, 1905), relation (26) (Winnikow, 1967), relation (27) (Takemura \& Yabe, 1998) and relation (28-29) with $f(\chi=1.5)=1.031$ (Figueroa \& Legendre, 2010) are reported in Figure 7 for comparison. All these expressions reproduce the decrease of the transfer coefficient, indicating that the decrease observed in Figure 7 is due to the combined evolutions of the diameter $\left\langle d_{e q}\right\rangle$ and the rise velocity $\left\langle V_{z}\right\rangle$ with the gas volume fraction. The major insight of the present work is that the mass transfer in a bubble column with a gas volume fraction as large as $16.5 \%$ is similar to that of a single bubble. This result is in agreement with the experiments of Abbas et al. (2009), which were carried out in a more complex configuration and for $\alpha_{G}$ up to $12 \%$.

According to the simulations reported in Figueroa \& Legendre (2010), the differences between the correlations for a single bubble are around 10\%. Expressions (27) and (26) give very close evolutions for hight Reynolds numbers and high Schmidt numbers. We can also observe that the differences between the predictions given by Eq. (2) and (28) are only due to the effect of the bubble shape on the mass transfer, which are given by Eq. 29 with $f(\chi=1.5)=1.031$. There is no significant effect of the bubble deformation in our study, the dominant effects in the variation of $k_{L}$ being due to the variation of the diameter and that of the rising velocity.

The absence of noticeable difference with the transfer of a single bubble results from the fact that the near velocity field structure on the front part of the bubble is not significantly changed by bubble interaction. As shown in Figueroa \& Legendre (2010), the total transfer is mainly controlled by the mass transfer on the front part of the bubble, which takes place across a very thin diffusion boundary layer $\delta_{D}$ that can be estimated as $\delta_{D} /\left\langle d_{e q}\right\rangle \approx P e^{-1 / 2}$. Typically, in our experiments the bubble diameters are in the range $2.1 \mathrm{~mm} \leq\left\langle d_{e q}\right\rangle \leq 4 \mathrm{~mm}$ and the corresponding slip velocities are $0.2 \mathrm{~m} \mathrm{~s}^{-1} \leq\left\langle V_{z}\right\rangle \leq 0.32 \mathrm{~m} \mathrm{~s}^{-1}$. The value of the Peclet number is thus $P e=O\left(410^{5}\right)$ and the diffusion boundary layer is $\delta_{D} /\left\langle d_{e q}\right\rangle \approx 0.005$ i.e. $\delta_{D} \approx 15 \mu \mathrm{m}$. For a Schmidt number around $500, \delta_{D}$ is about 20 times smaller than the dynamic boundary layer on the bubble surface. Very precise measurements of the velocity field around bubbles in a dense bubbly flow were reported by Roig \& Larue de Tounemine (2007). This study reveals that the velocity field on the front part of the bubble (i.e. the liquid pushed by the rising bubble) is mainly controlled by the bubble velocity and not significantly affected by the surrounding bubble induced agitation for $\alpha_{G}$ up to $15 \%$, while a more important effect is observed in the bubble wake. Since the transfer is mainly located on the front part of the bubble, the effect of the gas volume fraction remains low compared to the transfer from a single bubble of same diameter and same rising velocity. For a gas-liquid system with a smaller Peclet number, the concentration boundary layer would be thicker and one expect a stronger effect of the gas volume faction.

\section{Conclusions and perspectives}

In this work, the mass transfer have been investigated in a homogeneous dense bubble swarm up to $\alpha_{G}=16.5 \%$. The main characteristics of the bubble hydrodynamics have been measured. Bubble diameters and rising velocities have been presented versus the gas volume fraction. The correlation proposed by Riboux et al. (2010) for the vertical velocity was found to be valid for the range of gas volume fraction considered. Furthermore, this hindrance effect have been observed and confirmed with a non intrusive method by using shadow casting with a high-speed camera. The image processing has been performed thanks to the automatic detection of the bubbles in a very thin visualization field. 
In a second part, the mass transfer have been studied using the gassing-out method. Thanks to an accurate characterization of the interfacial area and the bubble dynamics, the mass transfer coefficient has been determined up to $\alpha_{G}=16.5 \%$. The experimental mass transfer coefficient was found to be very close to that of a single bubble when using a Reynolds number based on the equivalent diameter $\left\langle d_{e q}\right\rangle$ and the rising velocity $\left\langle V_{z}\right\rangle$.

Collective effect within the bubble swarm do not modify the mass transfer coefficient because at large Schmidt numbers, it takes place through a very thin concentration boundary layer located at the front of the bubble, which is not affected by hydrodynamical interactions between the bubbles. This result provides an a posteriori validation of mass transfer models for systems with high Peclet numbers that do not consider any gas volume fraction correction.

In a future work, we envisage to develop an improved PTV technique that could deal with large gas volume fraction and allow to check if the present results still hold for denser bubble swarm.

\section{Acknowledgements}

We thank the RHODIA Group for supporting this work. This research was carried out within the framework of a CIFRE-ANRT contract in collaboration with the FERMaT federation. We also thank Sebastien Cazin for its invaluable help on image processing and PTV methods and Gregory Ehses for his help in adapting the experimental set-up for this study.

AbBas, M, Billet, AM, \& Roig, V. 2009. Experiments on mass transfer and mixing in a homogeneous bubbly flow. Turbulence, Heat and Mass Transfer 6, K. Hanjalic, Y. Nagano and J. Jakirlic Editors, Begell House, Inc.

Ayed, H, Chahed, J, \& Roig, V. 2007. Hydrodynamics and mass transfer in a turbulent buoyant bubbly shear layer. AIChE Journal, 53, 2742-2753.

BEYER, WH. 1987. Standard Mathematical Tables. 28 edn. Boca Raton, CRC Press.

BoussinesQ, J. 1905. Calcul du pouvoir refroidissant des courants fluides. Mathematiques Pures et Appliquees, 6, 285-332.

Camacho Rubio, F, Luis Garcia, J, Molina, Y, \& Chisti, Y. 1999. Steady-state axial profiles of dissolved oxygen in tall bubble column bioreactors. Chemical Engineering Science, 11, 1711-1723.

Clift, R, Grace, JR, \& Weber, ME. 1978. Bubles, drops and particules. San Diego, Academic Press.

CockX, A, Do-Quang, Z, Line, A, \& Roustan, M. 1999. Use of computational fluid dynamics for simulating hydrodynamics and mass transfer in industrial ozonation towers. Chemical Engineering Science, 54, 5085-5090.

Darmana, D, Deen, N G, \& Kuipers, J A M. 2005. Detailed modeling of hydrodynamics, mass transfer and chemical reactions in a bubble column using a discrete bubble model. Chemical Engineering Science, 60, 3383 - 3404. 
Duhar, G, \& Colin, C. 2006. Dynamics of bubble growth and detachment in a viscous shear flow. Physics of Fluids, 18(077101).

Fayolle, Y, Cockx, A, Gillot, S, Roustan, M, \& Heduit, A. 2007. Oxygen transfer prediction in aeration tanks using CFD. Chemical Engineering Science, 62, 7163-7171.

FigueroA, B, \& Legendre, D. 2010. Mass or heat transfer from spheroidal gas bubbles rising through a stationary liquid. Chemical Engineering Science, 65, 6296 - 6309.

GARnier, C, LANCE, M, \& MARIÉ, JL. 2002. Measurement of local flow characteristics in buoyancy-driven bubbly flow at high void fraction. Experimental Thermal and Fluid Science, 26, 811-815.

Higbie, R. 1935. The rate of absorption of a pure gas into a still liquid during short periods of exposure. Transactions of the A.I.Ch.E., 31, 365 - 389.

HuAnG, Q., YANG, C., YU, G., \& MAO, ZS. 2010. CFD simulation of hydrodynamics and mass transfer in an internal air lift loop reactor using a steady two-fluid model. Chemical Engineering Science, 65, $5527-5536$.

LANCE, M, \& BATAille, J. 1991. Turbulence in the liquid phase of a uniform bubbly air-water flow. Journal of Fluid Mechanics, 222, 95-118.

Letzel, HM, Schouten, JC, Krishna, R, \& van Den Bleek CM. 1999. Gas holdup and mass transfer in bubble column reactors operated at elevated pressure. Chemical Engineering Science, 54, 2237-2246.

Lochiel, AC, \& CAlderbank, PH. 1964. Mass transfer in the continuous phase around axisymmetric bodies of revolution. Chemical Engineering Science, 19, 471-484.

Manasseh, R., Riboux, G., \& Risso, F. 2008. Sound generation on bubble coalescence following detachment. Intl J. Multiph. Flow, 34, 938 - 949.

Martin, M, Montes, FJ, \& Galan, MA. 2007. Bubble coalescence at sieve plates: II. Effect of coalescence on mass transfer. Superficial area versus bubble oscillations. Chemical Engineering Science, 62, 1741-1752.

Martínez-Mercado, J, Palacios-Morales, CA, \& Zenit, R. 2007. Measurement of pseudoturbulence intensity in monodispersed bubbly liquids for $10<\operatorname{Re}<500$. Physics of Fluids, 19(103302.1-103302.13).

Michaelides, EE. 2006. Particles, bubbles and drops: their motion, heat and mass transfer.

Moore, DW. 1963. The boundary layer on a spherical gas bubble. Journal of the Fluid Mechanics, 16, 161-176.

Nedeltchev, S, Jordan, U, \& Schumpe, A. 2007. Correction of the penetration theory based on mass-transfer data from bubble columns operated in the homogeneous regime under high pressure. Chemical Engineering Science, 62, 6263 - 6273. 
Riboux, G. 2007. Hydrodynamique d'un essaim de bulles en ascension. Ph.D. thesis.

Riboux, G, Risso, F, \& Legendre, D. 2010. Experimental characterization of the agitation generated by bubbles rising at high Reynolds number. Journal of Fluid Mechanics, 643, 509539.

Roig, V, \& LaRue De Tounemine, A. 2007. Measurement of interstitial velocity of homogeneous bubbly flows at low to moderate void fraction. Journal of Fluid Mechanics, 572, 87-110.

Rusche, H, \& ISSA, RI. 2000. The effect of voidage on the drag force on particules, droplets and bubbles in dispersed two-phase Flow. Tech. rept. BRITE-EURAM III program.

Shimada, N, Tomiyama, A, \& Ozaki, T (eds). 2007. Numerical Prediction of Bubbly Flow in a Bubble Column with Chemisorption. ICMF, Leipzig, Germany.

TAKemura, F, \& YABE, A. 1998. Gas dissolution process of spherical rising bubbles. Chemical Engineering Science, 53, 2691-2699.

TALVy, S, CockX, A, \& LiNÉ, A. 2007. Modeling of oxygen mass transfer in a gas-liquid airlift reactor. American Institute of Chemical Engineers Journal, 53, 316-326.

WinNiKOW, S. 1967. Letters to the editor. Chemical Engineering Science, 22, 22-477.

Zenit, R, Koch, DL, \& SAngani, AS. 2001. Measurements of the average properties of a suspension of bubbles rising in a vertical channel. Journal of Fluid Mechanics, 429, 307-342. 


\section{Nomenclature}

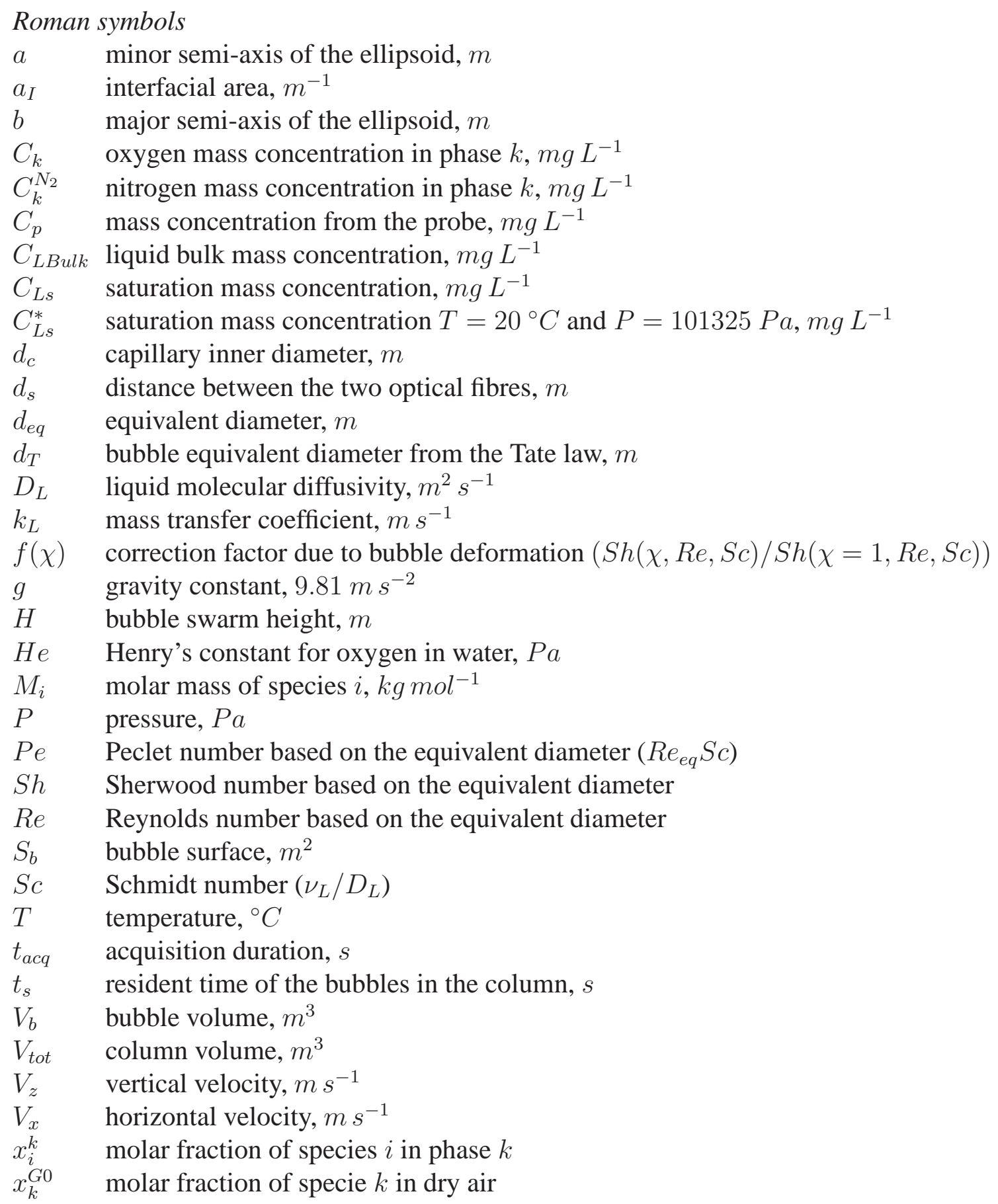




$\begin{array}{ll}\nu_{k} & \text { kinematic viscosity of phase } k, \mathrm{~m}^{2} \mathrm{~s}^{-1} \\ \rho_{k} & \text { density of phase } k, \mathrm{~kg} \mathrm{~m}^{-3} \\ \sigma & \text { surface tension, } N \mathrm{~m}^{-1} \\ \tau & \text { mass transfer time scale, } s \\ \tau_{p} & \text { probe response time scale, } s \\ \chi & \text { aspect ratio }(\chi=b / a)\end{array}$

Supercripts

Hig From Higbie theory

sat saturation

atm atmospheric conditions

\section{Subscripts}

G gas phase

$L \quad$ liquid phase

0 data obtained for a single bubble in quasi-static bubbling conditions

$\langle-\rangle \quad$ time averaged value

\section{List of Tables}

$1 \quad$ System properties at $T=20^{\circ} \mathrm{C}$ and $P^{a t m}=101325 \mathrm{~Pa} \ldots \ldots \ldots$

2 Liquid height above capillaries tip at $\alpha_{G}=0 \ldots \ldots \ldots \ldots$

\section{List of Figures}

1 Shadow casting set-up with a fixed-focus lens (upper view - BH: Back light or Halogen lighting) . . . . . . . . . . . . . . . . . . . . 18

2 Typical shadow casting raw images with bubble detection denoted by a white line. (a) $\alpha_{G}=0.45 \%$, (b) $\alpha_{G}=5.7 \%$, (c) $\alpha_{G}=11.9 \%$, (d) $\alpha_{G}=16.5 \%$. . . . . . . . 19

3 (a) Average bubble equivalent diameter: $\circ$ this work from PTV , $\square$ MartínezMercado et al. (2007) $\left(d_{c}=0.15 \mathrm{~mm}\right),-$ - Equation 20, - Equation 21. (b) Experimental interfacial area versus gas volume fraction: 'o' Equation 7, 'Equation $22 \ldots \ldots \ldots \ldots \ldots$

4 Time average bubble velocities - Results from the dual-tip optical probe for $\left\langle V_{z}\right\rangle$ : * Riboux et al. (2010), ○ This work - Results from PTV for $\square\left\langle V_{z}\right\rangle$ and $\square\left\langle V_{x}\right\rangle$ — Riboux et al. (2010) $V_{z 0}\left(1-\alpha_{G}^{0.49}\right),--$ Garnier et al. (2002) $V_{z 0}\left(1-\alpha_{G}^{1 / 3}\right)$. . 20

5 Typical evolution of the dissolved oxygen concentration for (a) $\alpha_{G}=0.6 \%$ and (b) $\alpha_{G}=15.2 \%$ : ○ oxygen porbe experimental data, — Equation $17 \ldots \ldots 21$

6 Time scale of the mass transfer versus the gas volume fraction. o experimental values determined by fitting the time evolution of the probe signal with Eq. 17 (see

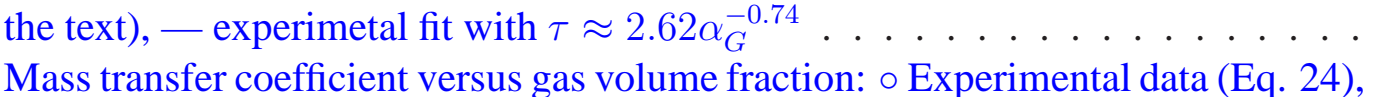

7 Mass transfer coefficient versus gas volume fraction: o Experimental data (Eq. 24),
$\triangle k_{L 0}$ single bubble (Eq. 28-29 with $\left.d_{e q 0}, V_{z 0}, \chi_{0}\right),-$ Eq. 2 (Boussinesq, 1905), -- Eq. 26 (Winnikow, 1967), -. Eq. 27 (Takemura \& Yabe, 1998), - Eq. 28-29 with $\chi=1.5$ (Figueroa \& Legendre, 2010) . . . . . . . . . . . . . . 22 


\begin{tabular}{c|c|c}
\hline$\rho_{L}$ & 998.2 & $\mathrm{~kg} \mathrm{~m}^{-3}$ \\
$\mu_{L}$ & $1.00210^{-3}$ & $\mathrm{Pas}$ \\
$\rho_{G}$ & 1.2 & $\mathrm{~kg} \mathrm{~m}^{-3}$ \\
$\mu_{G}$ & $1810^{-6}$ & $\mathrm{Pas}$ \\
$\sigma$ & $7310^{-3}$ & $\mathrm{Nm}^{-1}$ \\
$D_{L}$ & $210^{-9}$ & $\mathrm{~m}^{2} \mathrm{~s}^{-1}$ \\
$D_{L}^{N_{2}}$ & $1.6510^{-9}$ & $\mathrm{~m}^{2} \mathrm{~s}^{-1}$ \\
$\mathrm{He}\left(\mathrm{O}_{2}-\mathrm{H}_{2} \mathrm{O}\right)$ & $4.0510^{9}$ & $\mathrm{~Pa}$ \\
$\mathrm{He}\left(\mathrm{N}_{2}-\mathrm{H}_{2} \mathrm{O}\right)$ & $8.1510^{9}$ & $\mathrm{~Pa}$ \\
$\mathrm{P}^{s a t}\left(\mathrm{H}_{2} \mathrm{O}\right)$ & 2337 & $\mathrm{~Pa}$ \\
$M_{\mathrm{H}_{2} O}$ & $18.01510^{-3}$ & $\mathrm{~kg} \mathrm{~mol}^{-1}$ \\
$M_{\mathrm{O}_{2}}$ & $3210^{-3}$ & $\mathrm{~kg} \mathrm{~mol}^{-1}$ \\
$M_{N_{2}}$ & $2810^{-3}$ & $\mathrm{~kg} \mathrm{~mol}^{-1}$ \\
$x_{\mathrm{O}_{2}}^{G}$ & $20.9 \%$ & - \\
$x_{N_{2}}^{G 0}$ & $79.1 \%$ & - \\
\hline
\end{tabular}

Table 1: System properties at $T=20^{\circ} \mathrm{C}$ and $P^{a t m}=101325 \mathrm{~Pa}$

\begin{tabular}{c|c}
\hline$\alpha_{G}$ & Liquid height $[\mathrm{cm}]$ \\
\hline$\alpha_{G}<11 \%$ & 75.1 \\
$\alpha_{G} \geq 11$ & 64.2 \\
\hline
\end{tabular}

Table 2: Liquid height above capillaries tip at $\alpha_{G}=0$ 


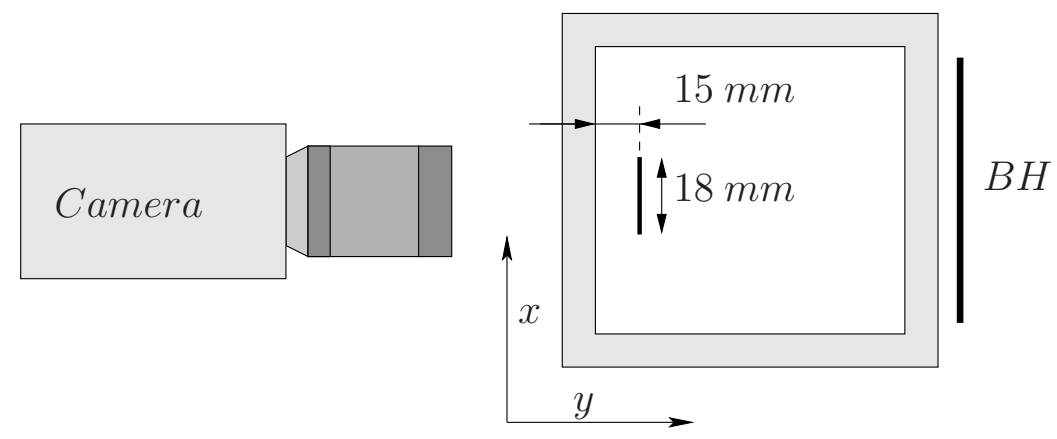

Figure 1: Shadow casting set-up with a fixed-focus lens (upper view - BH: Back light or Halogen lighting) 


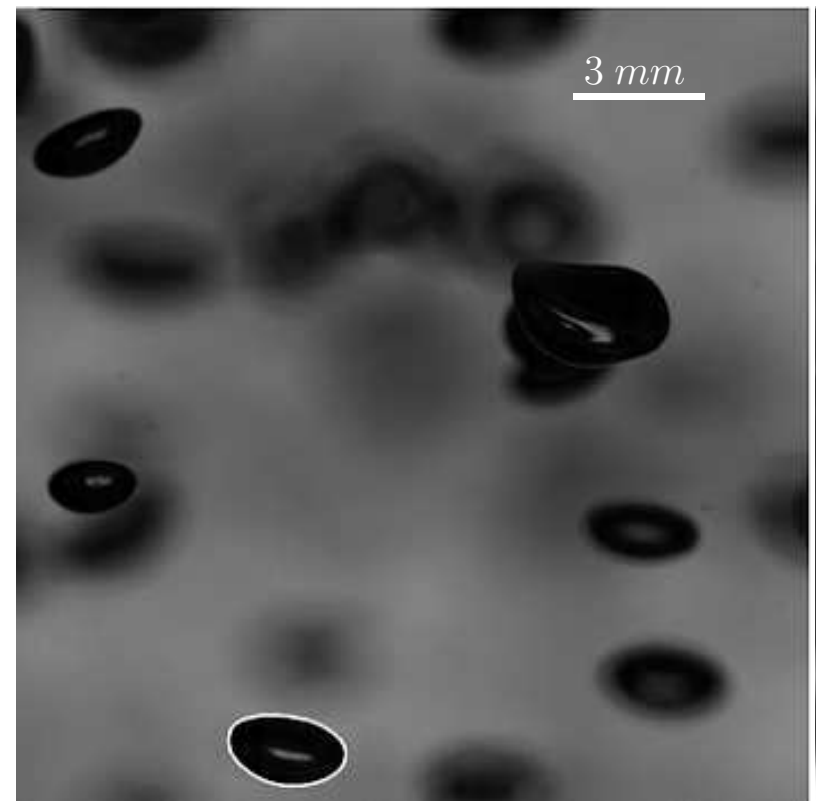

(a)

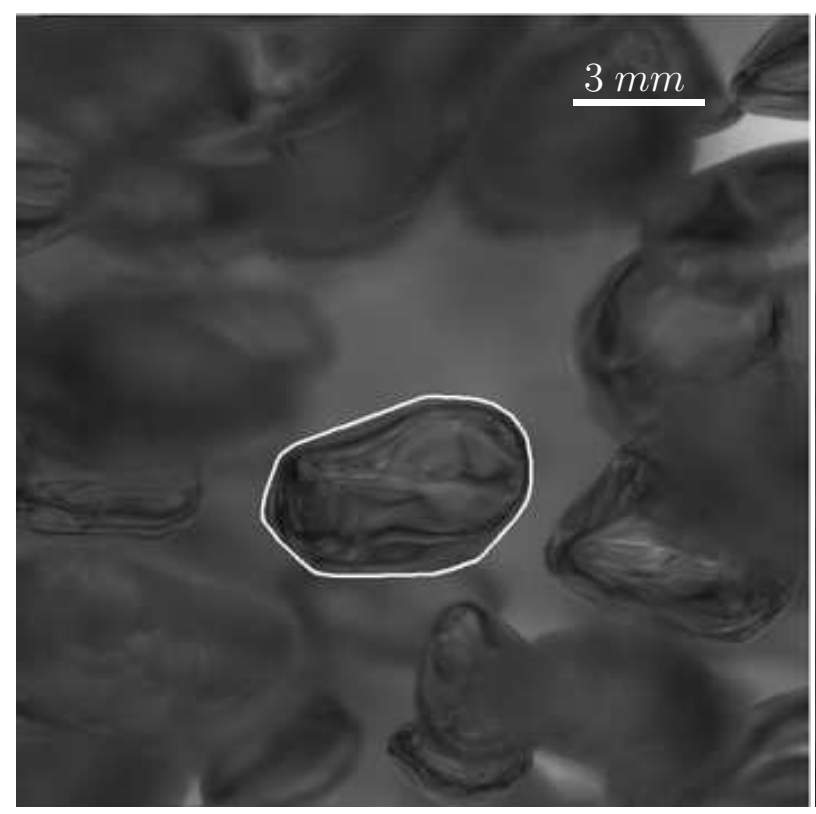

(c)

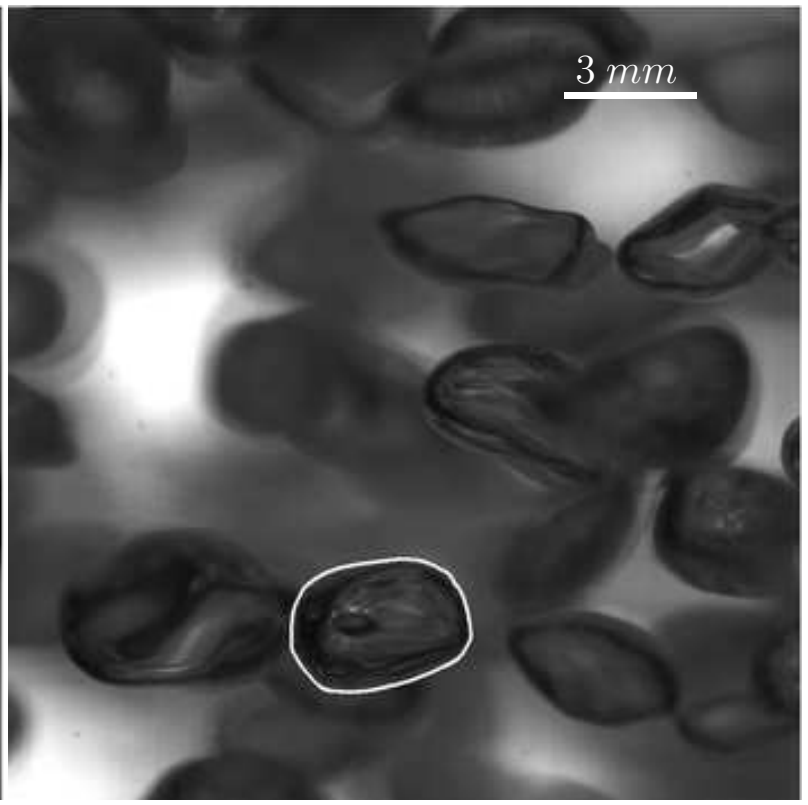

(b)

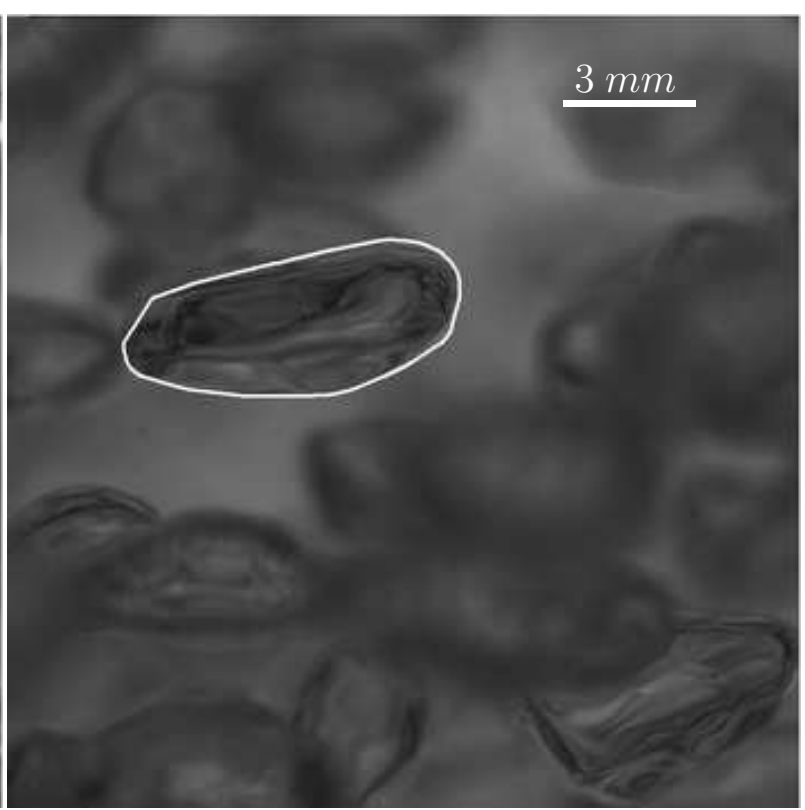

(d)

Figure 2: Typical shadow casting raw images with bubble detection denoted by a white line. (a) $\alpha_{G}=0.45 \%$, (b) $\alpha_{G}=5.7 \%$, (c) $\alpha_{G}=11.9 \%$, (d) $\alpha_{G}=16.5 \%$. 


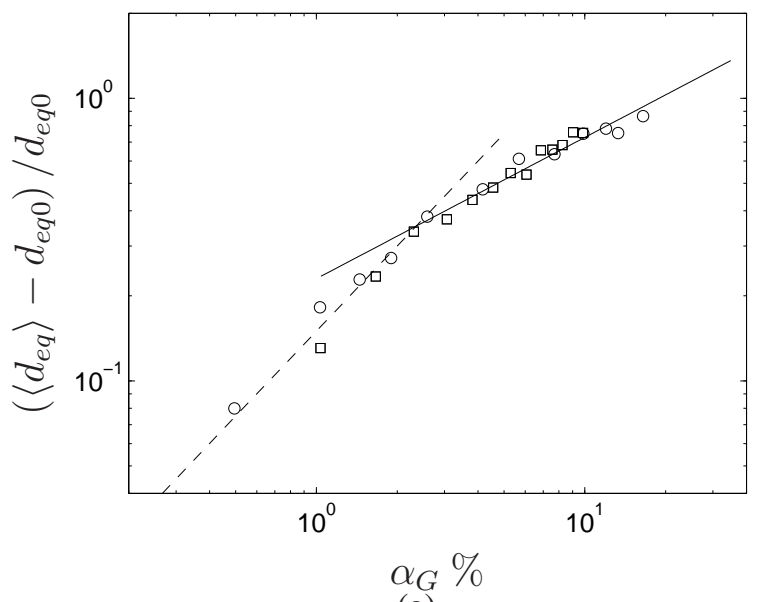

(a)

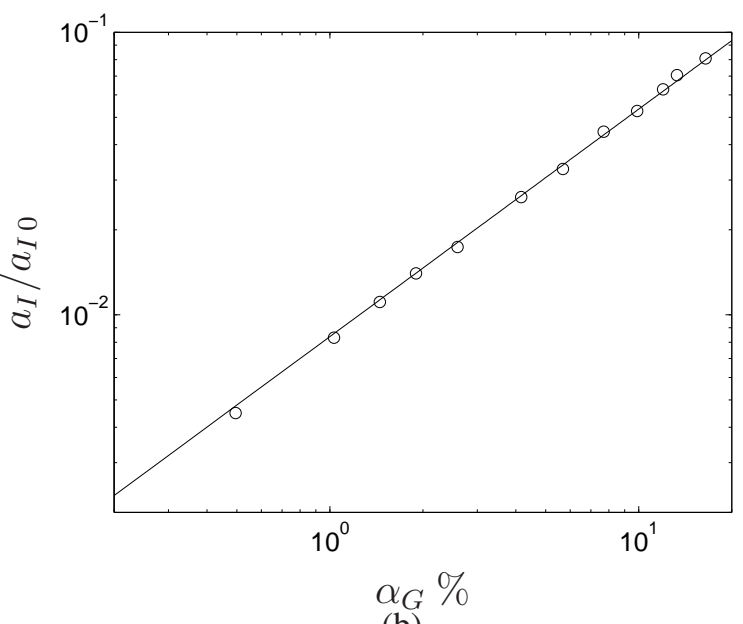

(b)

Figure 3: (a) Average bubble equivalent diameter: $\circ$ this work from PTV , $\square$ Martínez-Mercado et al. (2007) $\left(d_{c}=0.15 \mathrm{~mm}\right),-$ - Equation 20, - Equation 21. (b) Experimental interfacial area versus gas volume fraction: 'o' Equation 7, '-' Equation 22

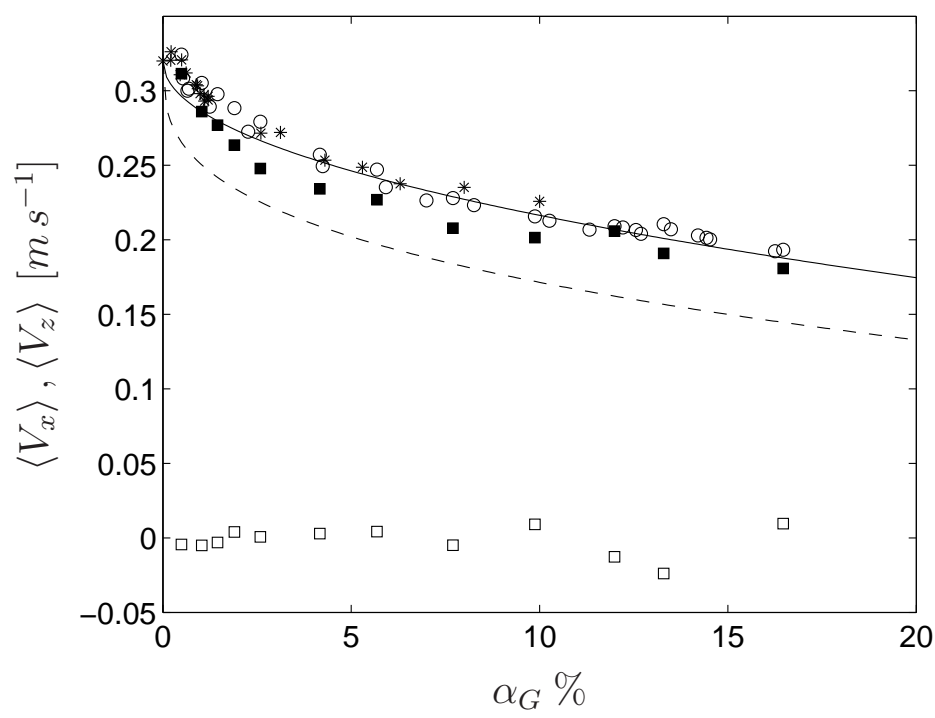

Figure 4: Time average bubble velocities - Results from the dual-tip optical probe for $\left\langle V_{z}\right\rangle$ : * Riboux et al. (2010), o This work - Results from PTV for $\boldsymbol{\square}\left\langle V_{z}\right\rangle$ and $\square\left\langle V_{x}\right\rangle-$ - Riboux et al. (2010) $V_{z 0}\left(1-\alpha_{G}^{0.49}\right),--$ Garnier et al. (2002) $V_{z 0}\left(1-\alpha_{G}^{1 / 3}\right)$ 


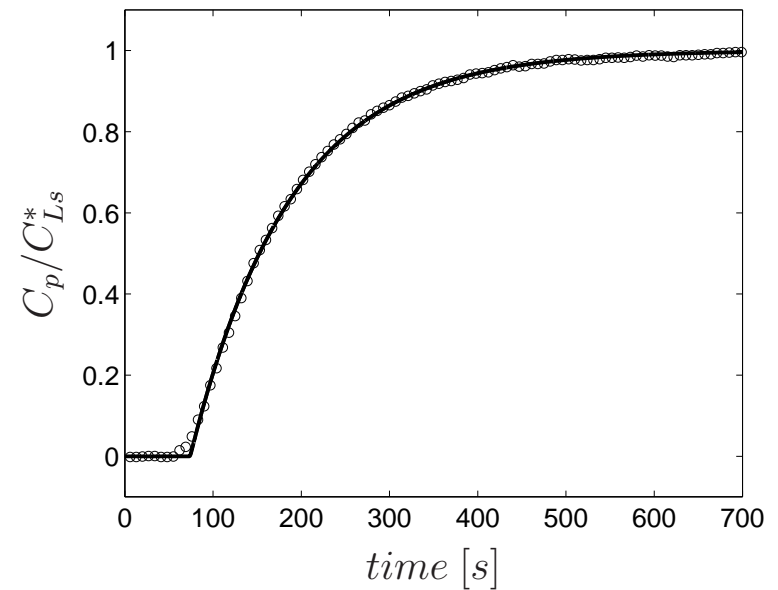

(a)

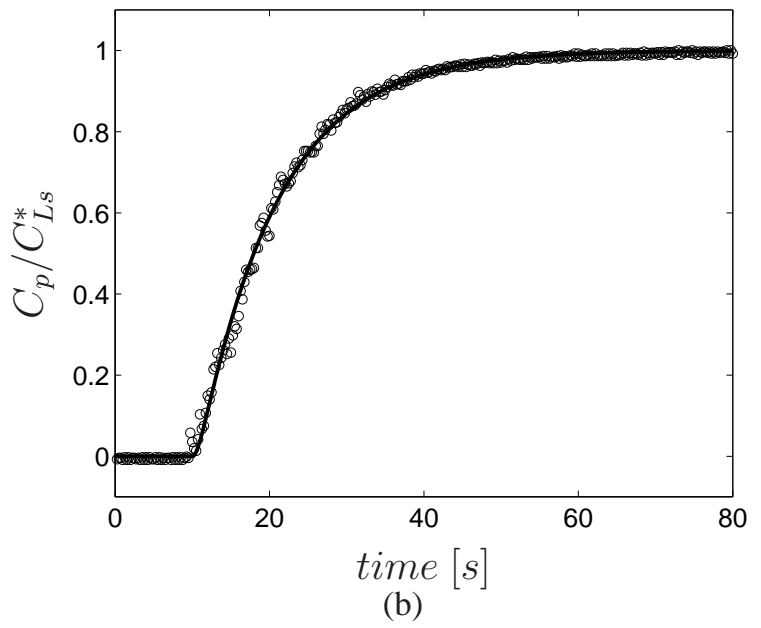

(b)

Figure 5: Typical evolution of the dissolved oxygen concentration for (a) $\alpha_{G}=0.6 \%$ and (b) $\alpha_{G}=15.2 \%$ : o oxygen porbe experimental data, - Equation 17

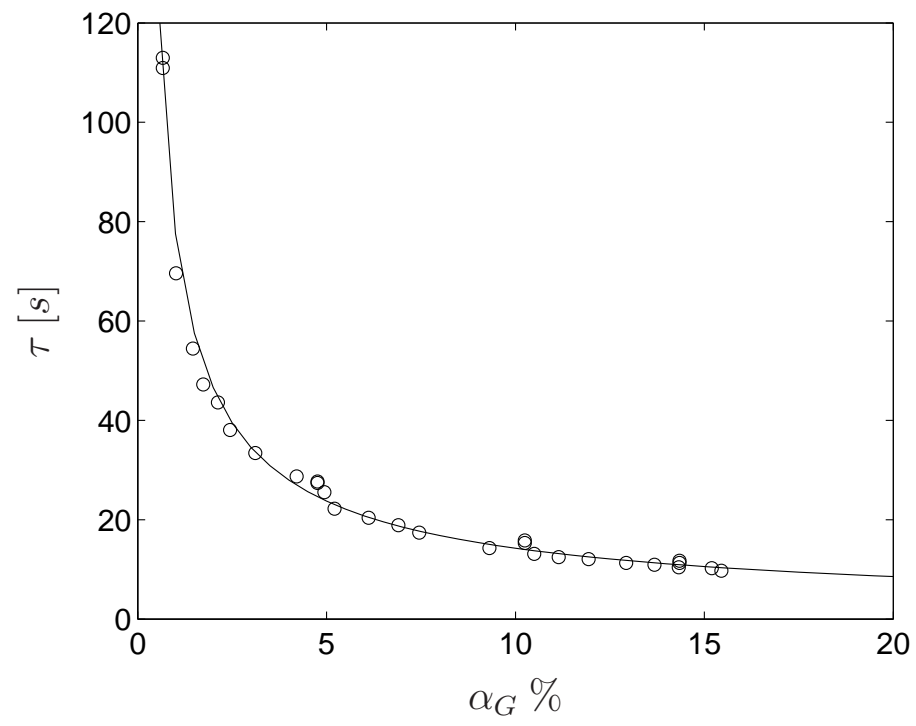

Figure 6: Time scale of the mass transfer versus the gas volume fraction. o experimental values determined by fitting the time evolution of the probe signal with Eq. 17 (see the text), experimetal fit with $\tau \approx 2.62 \alpha_{G}^{-0.74}$ 


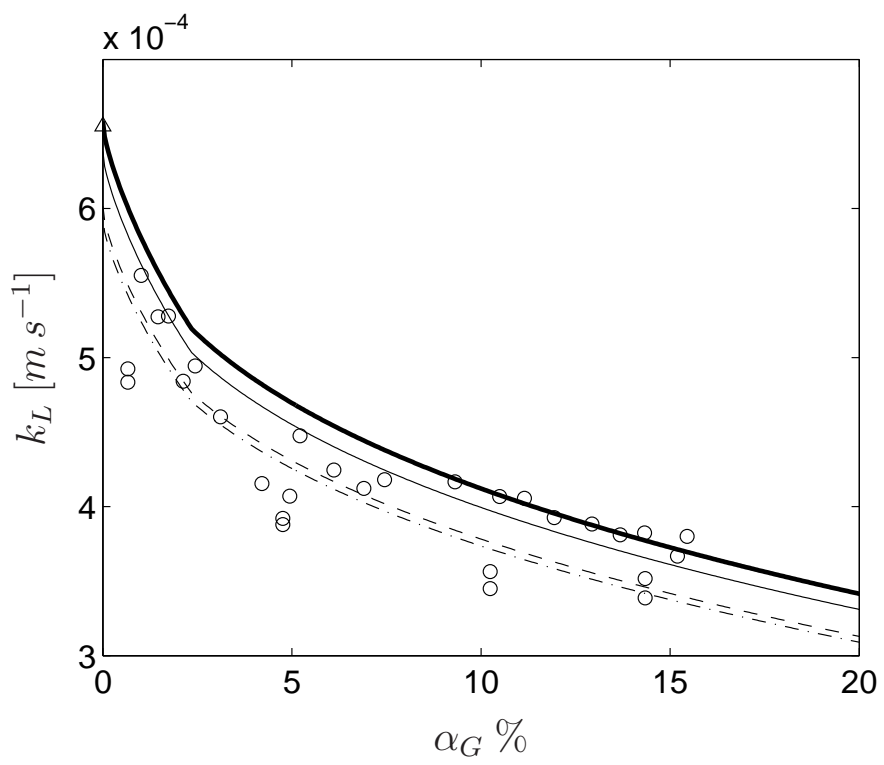

Figure 7: Mass transfer coefficient versus gas volume fraction: $\circ$ Experimental data (Eq. 24), $\triangle k_{L 0}$ single bubble (Eq. 28-29 with $d_{e q 0}, V_{z 0}, \chi_{0}$ ), - Eq. 2 (Boussinesq, 1905) , -- Eq. 26 (Winnikow, 1967), -. Eq. 27 (Takemura \& Yabe, 1998), - Eq. 28-29 with $\chi=1.5$ (Figueroa \& Legendre, 2010) 